\title{
PENGUATAN EKONOMI DIGITAL MELALUI PENGEMBANGAN "DIGITAL ENTREPRENEURSHIP” BAGI PELAKU UMKM DI DESA KERINJING OGAN ILIR SUMATERA SELATAN
}

\author{
Hera Febria Mavilinda'), Akhmad Nazaruddin"1), Nofiawaty'1), (slahuddin Daud'1), Lina Dameria S.1) \\ 1)Jurusan Manajemen, Fakultas Ekonomi, Universitas Sriwijaya, Palembang, Sumatera Selatan, Indonesia \\ Corresponding author: Hera Febria Mavilinda \\ E-mail : herafebria@fe.unsri.ac.id
}

Diterima 22 November 2021, Disetujui 27 November 2021

\begin{abstract}
ABSTRAK
Kebijakan pemerintah Indonesia untuk mempercepat pertumbuhan ekonomi digital menuntut para pelaku UMKM untuk dapat bertransformasi ke arah digitalisasi melalui pengembangan Kewirausahaan Digital (Digital Entrepreneurship). Namun demikian, pengembangan Digital Entrepreneurship di Indonesia dinilai masih rendah. Keterbatasan kemampuan UMKM dalam menggunakan teknologi serta kurangnya edukasi dan pemahaman literasi digital disinyalir menjadi hambatan dalam pengembangan Digital Entrepreneurship. Permasalahan ini juga dirasakan oleh para pelaku UMKM di Desa Kerinjing Ogan Ilir Sumatera Selatan. Tujuan dari kegiatan ini adalah untuk pengembangan dan penguatan literasi Digital Entrepreneurship serta memotivasi para pelaku UMKM agar dapat bertransformasi ke arah digitalisasi dalam menjalankan bisnisnya. Khalayak sasaran dalam kegiatan pengabdian masyarakat ini adalah para pelaku UMKM di Desa Kerinjing yang berjumlah \pm 30 orang dengan jenis usaha bergerak dibidang pengolahan makanan, minuman, konveksi dan pertanian. Metode pelaksanaan kegiatan ini dilakukan dalam bentuk penyuluhan (ceramah), tutorial dan diskusi interaktif. Melalui pelatihan dan pendampingan dalam pengembangan "Digital Entrepreneurship" bagi pelaku UMKM di Desa Kerinjing diharapkan dapat meningkatkan pengetahuan dan pemahaman literasi digital serta menumbuhkan motivasi bagi UMKM agar dapat bertransformasi ke arah digitalisasi. Pelatihan dan pendampingan ini juga diharapkan dapat menciptakan dan mengembangkan strategi bisnis yang lebih inovatif serta berdaya saing global yang dapat membantu penciptaan lapangan kerja dan meningkatan perekonomian desa.
\end{abstract}

Kata kunci: digital entrepreneurship; ekonomi digital; UMKM.

\begin{abstract}
Indonesian government's policy for accelerating rapidly the digital economic growth requires MSME to transform towards digitalization through the development of Digital Entrepreneurship. However, the development of Digital Entrepreneurship in Indonesia is still considered low. The limited ability of MSMEs in using technology and the lack of education and understanding of digital literacy are alleged to be obstacles in the development of Digital Entrepreneurship. This problem is also felt by MSME in Kerinjing Ogan Ilir, South Sumatra. The purpose of this activity is to develop and strengthen Digital Entrepreneurship literacy and motivate MSME to be able to transform towards digitalization in doing their business. The target audience in this community service activity are MSME in Kerinjing Ogan llir, South Sumatera, totaling 30 people with the type of business engaged in food processing, beverages, convection and agriculture. The method of implementing this activity is using socialization through presentations, tutorials and interactive discussions. Through training and mentoring in the development of "Digital Entrepreneurship" for MSME in Kerinjing Ogan llir, South Sumatera, it is expected to increase knowledge and understanding of digital literacy and bulid a motivation for MSMEs to be able to transform towards digitalization. This training and mentoring are also expected to create and develop more innovative and globally competitive business strategies that can help create jobs and improve the economy in Kerinjing, Ogan llir, South Sumatera.
\end{abstract}

Keywords: digital entrepreneurship; digital economic; MSMEs.

\section{PENDAHULUAN}

Revolusi industri 4.0 telah mendorong terciptanya konsep ekonomi digital di Indonesia. Menurut Kasidi (2020) pertumbuhan ekonomi digital dicerminkan dari semakin berkembangnya bisnis atau kegiatan perdagangan berbasis teknologi informasi dan internet. Kebijakan pemerintah untuk 
mempercepat pertumbuhan ekonomi digital memberikan peluang yang besar bagi para pelaku industri bisnis termasuk pelaku usaha mikro kecil menengah (UMKM) dalam mengembangkan usahanya dan memperluas jangkauan pasar. Kebijakan ini selaras dengan visi negara Indonesia untuk menjadi negara digital ekonomi terbesar di Kawasan Asia Tenggara di tahun 2020, yang salah satu kebijakannya berfokus terhadap penguatan pelaku UMKM dan start up lokal (Ismansyah \& Kranggan, 2020).

Hasil riset Deloitte tahun 2020 menyatakan bahwa UMKM di Indonesia menyumbang $60,34 \%$ dari Produk Domestik Bruto (PDB) Indonesia dan $97 \%$ terhadap penyerapan pasar tenaga kerja, sehingga partisipasi aktif dari para pelaku UMKM sangat dibutuhkan dalam membantu percepatan ekonomi digital (Deloitte, 2021). Untuk mendukung hal tersebut, para pelaku UMKM dituntut agar dapat bertransformasi ke arah digitalisasi melalui pengembangan Kewirausahaan Digital (Digital Entrepreneurship).

Digital Entrepreneurship merupakan kegiatan kewirausahaan dengan memanfaatkan teknologi digital yang menghasilkan suatu model bisnis baru yang lebih produktif dan berdaya saing global (Giones \& Brem, 2017). Selama ini, paradigma sebagian besar masyarakat Indonesia terhadap Digital Entrepreneurship lebih banyak berorientasi terhadap pemasaran digital (digital marketing), padahal tidak hanya sebatas itu, Digital Entrepreneurship mencakup beberapa hal penting lainnya seperti : menemukan pelanggan, merancang dan menawarkan produk melalui Platform Digital, menemukan peluang baru untuk berkolaborasi dan mitra usaha, mempelajari pasar untuk mengembangkan usaha dan membangun keunggulan bersaing, perluasan jaringan pemasaran dan distribusi, serta pengajuan permodalan serta pembayaran secara digital (Arianto, 2020). Pengembangan Digital Entrepreneurship diharapkan mampu mendukung penguatan ekonomi digital Indonesia di tahun 2025 menjadi yang terbesar di Asia Tenggara, serta turut mendukung percepatan pertumbuhan ekonomi nasional secara berkelanjutan. Selain itu, Digital Entrepreneurship dapat menjadi salah satu alternatif penyelamatan sektor UMKM dari krisis akibat pandemi COVID-19 yang terjadi sejak awal tahun 2020 (Avriyanti, 2021).

Selama pandemi, terjadi perubahan pola perilaku pembelian konsumen dari offline ke online. Survey dari Deloitte di tahun 2020 menunjukkan bahwa $78 \%$ pengguna internet di Indonesia membeli produk secara online melalui perangkat seluler (Deloitte, 2020). Perubahan perilaku konsumen tersebut membuat hampir seluruh sektor bisnis harus beradaptasi melalui transformasi digital dalam menjalankan bisnisnya (Mavilinda., et al, 2021). Bahkan dalam rapat terbatas yang diselenggarakan oleh presiden Republik Indonesia (RI) pada agustus 2020, mengungkapkan bahwa pandemi menjadi momentum bagi para pengusaha untuk melakukan percepatan transformasi digital (Kompas, 2020). Oleh karena itu, pengembangan Digital Entrepreneurship merupakan langkah yang tepat dalam menghadapi situasi pandemi dan perubahan perilaku konsumen saat ini. Melalui Digital Entrepreneurship, UMKM tidak hanya dapat memperluas jaringan pemasaran tetapi juga dapat menciptakan dan mengembangkan strategi bisnis baru untuk meningkatkan daya saing UMKM di pasar global.

Namun demikian, pengembangan Digital Entrepreneurship di Indonesia dinilai masih rendah, hal inilah yang menjadi penyebab lemahnya daya saing UMKM Indonesia di pasar global. Menurut data dari Kementerian Koperasi dan UMKM tercatat hanya sebesar $16 \%$ dari total 64 juta lebih UMKM yang masuk kedalam ekosistem digital per Oktober 2020 (Katadata, 2021). Apabila dilihat dari tingkat kesiapan UMKM dalam melakukan transormasi digital, berdasarkan hasil survey dari Katadata Insight Center (KIC) tingkat kesiapan UMKM untuk melakukan transformasi digital belum terlalu tinggi (Katadata, 2020). Beberapa masalah yang dihadapi UMKM dalam melakukan transformasi digital diantaranya rendahnya motivasi UMKM untuk mendigitalisasikan bisnisnya, kurangnya edukasi dan pengetahuan literasi digital dari para pelaku UMKM serta keterbatasan kemampuan UMKM dalam menggunakan teknologi (Sumarni \& Melinda, 2020).

Permasalahan ini juga dirasakan oleh UMKM yang ada di Provinsi Sumatera Selatan (Sumsel) baik di wilayah perkotaan maupun pedesaan. Data dari pengamat ekonomi Sumsel, bahwa UMKM yang aktif dalam platform digital baru mencapai $8 \%$ dari 3,97 juta keseluruhan pengguna platform digital, penyebabnya adalah masih banyak UMKM yang belum memanfaatkan penggunaan platform digital untuk menjalankan bisnisnya karena keterbatasan pengetahuan dan kemampuan (Sumber : Sumsel.idntimes.com, 2020).

Desa kerinjing merupakan salah satu desa yang ada di wilayah Provinsi Sumatera Selatan dan merupakan desa binaan Universitas Sriwijaya. Desa kerinjing berada di Kecamatan Tanjung Raja Kabupaten Ogan Ilir Sumatera Selatan. Mata pencarian masyarakat 
yang ada di Desa Kerinjing mayoritas adalah dengan Bertani dan berdagang. Di Desa Kerinjing telah banyak terdapat pelaku UMKM home industry yang jenis usahanya meliputi : Usaha Kemplang panggang dan budidaya sirup jeruk kunci. Kegiatan UMKM yang ada di desa kerinjing memiliki peran yang penting dalam menciptakan lapangan pekerjaan bagi masyarakat desa serta menompang perekonomian di desa kerinjing.

Namun permasalahan yang terjadi saat ini, masih banyak pelaku UMKM desa kerinjing yang menjalankankan usahanya secara konvensional dan belum beralih ke arah digitalisasi. Hal ini dapat terlihat dari jangkauan pemasaran dan penjualan produk UMKM di desa kerinjing yang mayoritas adalah masyarakat desa kerinjing saja. Selain itu, berdasarkan informasi dari kepala desa kerinjing, selama 3 tahun terakhir jumlah pelaku UMKM di desa kerinjing belum menunjukkan peningkatan yang signifikan, bahkan sejak terjadinya pandemi terdapat beberapa UMKM yang memilih untuk menghentikan aktivitas usahanya karena penurunan penjualan. Padahal Desa Kerinjing memiliki lokasi yang cukup strategis karena berada di pinggir jalan besar sehingga memudahkan akses dan jangkauan pemasaran. Infrastruktur jaringan internet di Desa Kerinjing juga sudah cukup baik sehingga masyarakat di Desa Kerinjing dapat mengakses internet dengan cepat tanpa terkendala jaringan. Sayangnya kondisi ini belum dimanfaatkan oleh para pelaku UMKM untuk bertransformasi ke arah digitalisasi. Seperti diketahui bahwa era digitalisasi memberikan peluang yang sangat besar bagi para pelaku usaha untuk menciptakan dan mengembangkan bisnisnya serta menjangkau pemasaran yang lebih luas. Keterbatasan dalam menggunakan teknologi serta kurangnya edukasi dan pemahaman literasi digital disinyalir menjadi hambatan dalam pengembangan Digital Entrepreneurship bagi pelaku UMKM di desa kerinjing.

Berdasarkan hal tersebut diatas, Adapun tujuan dari kegiatan pengabdian masyarakat ini adalah sebagai berikut :

1. Mendukung program kebijakan pemerintah dalam penguatan ekonomi digital melalui pengembangan Digital Entrepreneurship bagi pelaku UMKM di Desa Kerinjing.

2. Memberikan motivasi bagi para pelaku UMKM di desa kerinjing untuk dapat bertransformasi pada platform digital dalam menjalankan bisnisnya.

3. Penguatan literasi digital dan pemahaman mengenai konsep dan strategi Digital Entrepreneurship bagi pelaku UMKM di desa kerinjing agar dapat menciptakan dan mengembangkan strategi bisnis baru untuk meningkatkan daya saing UMKM di pasar global.

\section{METODE}

Khalayak Sasaran dan Metode Pelaksanaan

Khalayak sasaran pada kegiatan pengabdian masyarakat ini adalah para pelaku UMKM yang ada di Desa Kerinjing sebanyak lebih kurang 30 orang, dengan kriteria telah memiliki usaha berskala mikro kecil menengah yang sedang berjalan dan berada di Desa Kerinjing. Jenis usaha pelaku UMKM bergerak di berbagai bidang seperti bidang pengolahan makanan dan minuman, bidang konveksi, bidang agrobisnis, bidang peternakan dan lain sebagainya. Adapun metode pelaksanaan kegiatan pengabdian masyarakat ini dilakukan secara offline di Desa Kerinjing Ogan Ilir Sumatera Selatan dengan tetap menerapkan protokol kesehatan. Metode kegiatan pengabdian masyarakat dilakukan dalam bentuk penyuluhan (ceramah), tutorial dan diskusi interaktif dengan para peserta.

\section{Kerangka Pemecahan Masalah}

Pengembangan Kewirausahaan Digital (Digital Entrepreneurship) bagi para pelaku UMKM diharapkan mampu mendukung penguatan ekonomi digital Indonesia di tahun 2025 menjadi yang terbesar di Asia Tenggara, serta turut mendukung percepatan pertumbuhan ekonomi nasional secara berkelanjutan. Pengembangan Digital Entrepreneurship juga menjadi salah satu alternatif penyelamatan sektor UMKM dari krisis akibat pandemi COVID-19. Kegiatan pelatihan dan pendampingan dalam pengembangan Digital Entrepreneurship bagi pelaku UMKM di Desa Kerinjing diharapkan mampu meningkatkan pengetahuan dan pemahaman literasi digital serta menumbuhkan motivasi bagi UMKM untuk dapat bertransformasi ke arah digitalisasi, sehingga para pelaku UMKM di desa kerinjing dapat menciptakan dan mengembangkan strategi bisnis yang lebih inovatif serta berdaya saing global yang dapat membantu penciptaan lapangan kerja dan meningkatan perekonomian di desa Kerinjing. Adapun kerangka pemecahan masalah ditunjukkan pada gambar di bawah ini : 

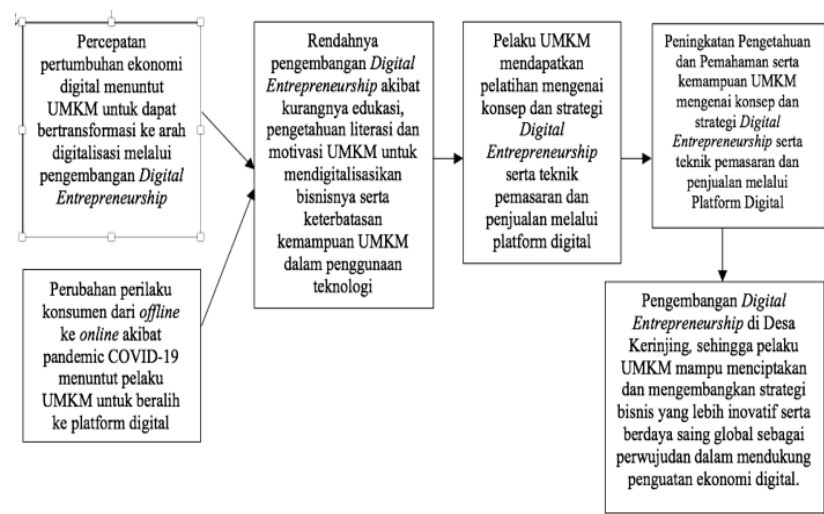

Gambar 1. Kerangka Pemecahan Masalah

\section{HASIL DAN PEMBAHASAN \\ Uraian dan Hasil Kegiatan Pengabdian Masyarakat}

Kegiatan pengabdian masyarakat ini dilaksanakan di Desa Kerinjing, Kabupaten Ogan Ilir, Provinsi Sumatera Selatan. Kegiatan ini dilaksanakan sebanyak 3 (tiga) kali yaitu kegiatan pertama berupa peninjauan lokasi dan pemetaan UMKM di Desa Kerinjing, kegiatan kedua yaitu acara inti berupa penyuluhan atau ceramah dan diskusi interaktif kepada para pelaku UMKM di Desa Kerinjing dan kegiatan ketiga berupa monitoring dan pendampingan kepada pelaku UMKM yang ada di Desa Kerinjing. Kegiatan ini diikuti oleh 25 orang peserta pelaku UMKM dengan jenis usaha yang bergerak di bidang pengolahan makanan dan minuman yaitu Kemplang Tunu dan sirup jeruk kunci, bidang konveksi yaitu menjahit baju-baju khas Palembang, bidang agrobisnis dan bidang peternakan. Pelaksanaan kegiatan pengabdian masyarakat ini dlakukan secara offline dengan menerapkan protokol kesehatan selama pelaksanaan kegiatan seperti : memakai masker, mencuci tangan dan menjaga jarak. Profil peserta kegiatan pengabdian masyarakat ini dapat dilihat pada Tabel 1.

Tabel 1. Profil Peserta Kegiatan Pengabdian Masyarakat

\begin{tabular}{cccc}
\hline Deskripsi & Keterangan & Jumlah & Persentase \\
\hline \multirow{2}{*}{ Jenis Kelamin } & Laki-Laki & 11 & $44 \%$ \\
& Wanita & 14 & $56 \%$ \\
\hline \multirow{4}{*}{ Umur } & $18-25$ Tahun & 4 & $16 \%$ \\
& $25-35$ Tahun & 6 & $24 \%$ \\
& $35-45$ Tahun & 9 & $36 \%$ \\
& $>45$ Tahun & 6 & $24 \%$ \\
\hline \multirow{4}{*}{ Jenis Usaha } & Kuliner & 15 & $60 \%$ \\
& Konveksi & 2 & $8 \%$ \\
& Agrobisnis & 4 & $16 \%$ \\
& Peternakan & 4 & $16 \%$ \\
\hline Memanfaatkan & Sudah & 5 & $20 \%$ \\
\hline
\end{tabular}

Berdasarkan Tabel 1, jumlah peserta kegiatan pengabdian masyarakat ini adalah sebanyak 25 orang yang terdiri dari 11 orang
(44\%) laki-laki dan 14 orang (56\%) adalah perempuan. Mayoritas pelaku UMKM di Desa Kerinjing berusia $35-45$ tahun yaitu sebanyak 9 orang (36\%), sisanya sebanyak 4 orang $(16 \%)$ berusia $18-25$ tahun, sebanyak 6 orang $(24 \%)$ berusia $25-25$ tahun dan sebanyak 6 orang $(24 \%)$ berusia diatas 45 tahun. Pelaku UMKM sebagian besar memiliki jenis usaha yang bergerak di bidang kuliner yaitu sebanyak 15 orang $(60 \%)$, sedangkan sisanya sebanyak 2 orang $(8 \%)$ bergerak di bidang konveksi, sebanyak masing-masing 4 orang (16\%) bergerak di bidang agrobisnis dan peternakan. Dari 25 pelaku UMKM yang menjadi peserta dalam pelatihan Digital Entrepreneurship ini, sebanyak $80 \%$ peserta atau 20 orang peserta mengaku belum memanfaatkan platform digital seperti platform media sosial instgram dan facebook maupun platform e-commerce seperti shopee dan tokopedia dalam menjual dan memasarkan produknya, sedangkan sebanyak 5 orang $(20 \%)$ mengaku menggunakan platform media sosial instgram dan facebook dalam menjalankan bisnisnya.

Pelaksanaan kegiatan pengabdian masyarakat ini dilakukan dalam 3 (tiga) pertemuan dengan tahapan kegiatan sebagai berikut :

\section{Survey Lokasi dan Pemetaan UMKM}

Dalam kegiatan ini tim pengabdian masyarakat melakukan koordinasi dengan perangkat desa terkait dengan dengan jadwal pelaksanaan kegiatan, melakukan peninjauan pada lokasi pengabdian dan melakukan pemetaan sekaligus survey di beberapa pelaku UMKM yang ada di Desa Kerinjing untuk memperoleh data mengenai jenis usaha pelaku UMKM dan bagaimana pelaksanaan kegiatan usaha yang saat ini mereka jalani. Pada kegiatan ini tim pengabdian masyarakat berkesempatan untuk mengunjungi dan melihat usaha yang dijalankan oleh UMKM yang ada di Desa Kerinjing seperti : Usaha penjualan kemplang tunu dan konveksi.

\section{Penyuluhan (Ceramah) dan Diskusi}

Kegiatan kedua dilaksanakan dengan agenda memberikan penyuluhan (ceramah) kepada para pelaku UMKM di Desa Kerinjing mengenai Digital Entrepreneurship. Adapun tahapan pelaksanaan kegiatan ini adalah sebagai berikut :

\section{a. Acara Pembukaan.}

Kegiatan ini dimulai dengan acara pembukaan yaitu berupa kata sambutan dari Bapak Faisol Kimi selaku Kepala Desa Kerinjing Ogan Ilir Sumatera Selatan. Dalam sambutannya Bapak Faisal Kimi menyampaikan apresiasi dan antusiasnya terhadap tim pengabdian masyarakat 
Fakultas Ekonomi Universitas Sriwijaya yang telah menyelenggarakan kegiatan ini dalam rangka untuk pengembangan kewirausahaan digital kepada para pelaku UMKM yang ada di Desa Kerinjing. Melalui kegiatan ini diharapkan para pelaku UMKM di Desa Kerinjing yang saat ini masih banyak menjalankan usaha nya secara tradisional dapat segera bertransformasi ke arah digital sehingga memiliki daya saing untuk mengembangkan bisnisnya di tingkat lokal maupun global sebagai perwujudan dalam mendukung penguatan ekonomi digital.

\section{b. Kegiatan Penyuluhan (Ceramah) berupa penyampaian materi.}

Kegiatan ini berupa penyampaian materi dalam bentuk penyuluhan (ceramah) kepada para peserta. Adapun yang menjadi nara sumber dalam kegiatan penyuluhan ini adalah Ibu Hera Febria Mavilinda S.E., M.Si yang juga merupakan salah satu Tim Kegiatan Pengabdian Masyarakat. Materi yang disampaikan mengenai konsep dan strategi "Digital Entrepreneurship". Sebelum menyampaikan materi kepada peserta, terlebih dahulu dilakukan pre-test untuk melihat tingkat pemahaman awal dari para peserta mengenai Digital Entrepreneurship.

\section{c. Acara Diskusi}

Dalam kegiatan ini, setelah nara sumber menyampaikan materi mengenai Digital Entrepreneurship, dilakukan sesi diskusi dan tanya jawab kepada para peserta. Pada acara diskusi ini, para peserta sangat antusias dan aktif baik dalam bertanya maupun berbagi pengalaman mengenai kendala dan hambatan mereka untuk menjalankan bisnisnya secara digital.

\section{d. Evaluasi}

Sebelum sesi evaluasi dimulai, nara sumber melakukan review terlebih dahulu atas seluruh materi yang telah disampaikan. Kegiatan evaluasi dilakukan bertujuan untuk mengetahui tingkat pemahaman peserta terkait dengan konsep dan strategi Digital Entrepreneurship yang telah disampaikan. Evaluasi dilakukan dengan memberikan lembar pertanyaan tertulis kepada para peserta dalam bentuk Post Test. Selain itu tim pengabdian masyarakat juga membagikan lembar kuisioner berupa evaluasi penilaian peserta terhadap pelaksanaan kegiatan pengabdian masyarakat ini. Hal tersebut dilakukan untuk mendapatkan feedback dari para peserta atas manfaat yang dirasakan, kritik serta saran terhadap kegiatan ini, dengan tujuan sebagai bahan evaluasi untuk pelaksanaan kegiatan pengabdian masyarakat di waktu yang akan datang. Tabel 2 dibawah ini menunjukkan hasil Pre-Test dan Post Test dari para peserta terhadap tingkat pengetahuan mereka mengenai konsep dan strategi Digital Entrepreneurship sebelum dan sesudah dilakukan pelatihan :

Tabel 2. Hasil Distribusi dan frekuensi

Pengetahuan Peserta Sebelum dan Sesudah Pelatihan

\begin{tabular}{ccccc}
\hline \multirow{2}{*}{$\begin{array}{c}\text { Pengetahuan } \\
\text { Digital } \\
\text { Entrepreneurship }\end{array}$} & \multicolumn{2}{c}{ Sebelum } & \multicolumn{3}{c}{ Sesudah } \\
\cline { 2 - 5 } & Frekuensi & $\%$ & Frekuensi & $\%$ \\
\hline Sangat Baik & 0 & 0 & 12 & 48 \\
\hline Baik & 2 & 8 & 10 & 40 \\
\hline Cukup Baik & 8 & 32 & 3 & 12 \\
\hline Kurang Baik & 15 & 60 & 0 & 0 \\
\hline
\end{tabular}

Berdasarkan Tabel, dapat terlihat bahwa sebelum pelaksanaan pelatihan, pengetahuan peserta mengenai Digital Entrepreneurship mayoritas dalam kategori kurang baik yaitu sebanyak 15 orang $(60 \%)$, sedangkan sisanya sebanyak 8 peserta $(32 \%)$ dalam kategori cukup baik, sebanyak 2 peserta $(8 \%)$ dalam kategori Baik dan sebanyak 0 peserta dalam kategori sangat baik. Setelah dilakukan pelatihan dalam bentuk penyuluhan, terjadi peningkatan pengetahuan dan pemahaman peserta mengenai Digital Entrepreneurship yaitu sebanyak 12 peserta $(48 \%)$ dalam kategori sangat baik, 10 peserta $(40 \%)$ dalam kategori baik, 3 peserta $(12 \%)$ dalam kategori cukup baik dan 0 peserta dalam kategori kurang baik. Hal tersebut menunjukkan bahwa pelatihan ini memberikan hasil terhadap peningkatan pengetahuan dan pemahaman peserta mengenai konsep dan strategi Digital Entrepreneurship.

\section{e. Acara Penutupan}

Sebagai penutup acara kegiatan penyuluhan ini, dilakukan sesi foto bersama dengan seluruh peserta dan tim panitia kegiatan pengabdian masyarakat.

\section{Monitoring dan Pendampingan}

Kegiatan ini dilakukan dalam rangka melakukan monitoring dan pendampingan kepada beberapa pelaku UMKM yang ada di Desa Kerinjing sebagai bentuk tindak lanjut atas kegiatan penyuluhan mengenai Digital Entrepreneurship yang telah dilakukan oleh 
Tim Pengabdian Masyarakat sebelumnya. Dalam kegiatan ini, tim pengabdian masyarakat membantu beberapa pelaku UMKM yang ada di Desa Kerinjing untuk membuat akun bisnis di platform media sosial sebagai langkah awal bagi mereka untuk mulai beralih ke arah digital. Selain itu kegiatan ini juga dilakukan sebagai wadah konsultasi bagi beberapa pelaku UMKM yang menemui kendala atau hambatan dalam menjalankan usahanya secara digital.

\section{Pembahasan}

Kebijakan pemerintah Indonesia untuk mempercepat pertumbuhan ekonomi digital menuntut para pelaku UMKM untuk dapat bertransformasi ke arah digitalisasi melalui pengembangan Kewirausahaan Digital (Digital Entrepreneurship). Hal tersebut semakin diperkuat dengan munculnya wabah pandemi COVID-19 di awal tahun 2020 yang membuat terjadinya perubahan perilaku konsumen dalam pola pembelian barang dan jasa dari offline ke online. Perubahan perilaku konsumen tersebut membuat hampir seluruh sektor bisnis harus beradaptasi melalui transformasi digital dalam menjalankan bisnisnya (Mavilinda., et al, 2021). Digital Entrepreneurship merupakan kegiatan kewirausahaan dengan memanfaatkan teknologi digital yang menghasilkan suatu model bisnis baru yang lebih produktif dan berdaya saing global (Giones \& Brem, 2017). Orang - orang yang mengembangkan konsep Digital Entreprenuership dikenal sebagai wirausaha digital. Wira usaha digital adalah bagian sub kategori dari kewirausahaan dimana organisasi tradisional yang bergerak secara fisik didigatalisasikan, sehingga wirausaha tradisional berubah dalam bentuk usaha baru di era digital (Le Dinh et al., 2018).

Melalui Digital Entrepreneurship, UMKM tidak hanya dapat memperluas jaringan pemasaran tetapi juga dapat menciptakan dan mengembangkan strategi bisnis baru untuk meningkatkan daya saing UMKM di pasar global. Namun demikian, pengembangan Digital Entrepreneurship di Indonesia dinilai masih rendah. Permasalahan ini juga dirasakan oleh UMKM yang ada di Provinsi Sumatera Selatan (Sumsel) salah satunya UMKM yang ada di Desa Kerinjing Ogan Ilir Sumatera Selatan. Para pelaku UMKM di Desa Kerinjing mayoritas masih menjalankan usahanya dengan cara konvensional. Keterbatasan dalam menggunakan teknologi serta kurangnya edukasi dan pemahaman literasi digital disinyalir menjadi hambatan dalam pengembangan Digital Entrepreneurship bagi pelaku UMKM di desa kerinjing.

Merujuk pada kondisi diatas, tujuan dari kegiatan pengabdian ini yaitu : Untuk mendukung program kebijakan pemerintah dalam penguatan ekonomi digital melalui pengembangan Digital Entrepreneurship, Memberikan motivasi bagi para pelaku UMKM di Desa Kerinjing agar dapat bertransformasi pada platform digital dan Penguatan literasi digital dalam hal pemahaman konsep dan strategi Digital Entrepreneurship bagi para pelaku UMKM di Desa Kerinjing.

Saat ini para pelaku UMKM di Desa Kerinjing mayoritas masih banyak yang belum memahami konsep dan strategi dari Digital Entrepreneurship. Mereka hanya mengandalkan cara konvensional seperti pemasaran dan penjualan secara langsung kepada konsumen. Banyak dari mereka yang belum memanfaatkan platform digital melalui media sosial seperti Instagram dan facebook dalam memasarkan dan menjual produknya. Selain itu belum ada para pelaku UMKM di Desa Kerinjing yang menggunakan E-Commerce seperti Shopee dan Tokopedia dalam melakukan penjualan produk mereka.

Kendala yang dihadapi dari para pelaku

UMKM dalam pengembangan Digital Entrepreneurship di Desa Kerinjing adalah kurangnya edukasi, pengetahuan literasi dan motivasi UMKM untuk bertransformasi ke arah digitalisasi serta masih terbatasnya kemampuan UMKM dalam memanfaatkan teknologi informasi untuk menjalankan bisnisnya. Melalui pelatihan dan pendampingan dalam pengembangan "Digital Entrepreneurship" bagi pelaku UMKM di Desa Kerinjing diharapkan dapat meningkatkan pengetahuan dan pemahaman literasi digital serta menumbuhkan motivasi bagi UMKM agar dapat bertransformasi ke arah digitalisasi. Pelatihan dan pendampingan ini juga diharapkan dapat menciptakan dan mengembangkan strategi bisnis yang lebih inovatif serta berdaya saing global yang dapat membantu penciptaan lapangan kerja dan meningkatan perekonomian desa.

Berdasarkan dari hasil evaluasi sebelum dan setelah kegiatan pengabdian masyarakat ini dilakukan, tedapat peningkatan pengetahuan dan pemahaman literasi mengenai konsep dan strategi Digital entrepreneurship pada para pelaku UMKM di Desa Kerinjing Ogan Ilir, Sumatera Selatan. Lebih jauh, para pelaku UMKM juga menyampaikan komitmen mereka untuk dapat segera bertransformasi ke arah digital dalam menjalankan bisnisnya. Berikut ini dokumentasi dari hasil kegiatan pengabdian masyarakat yang telah dilaksanakan sebagai berikut : 


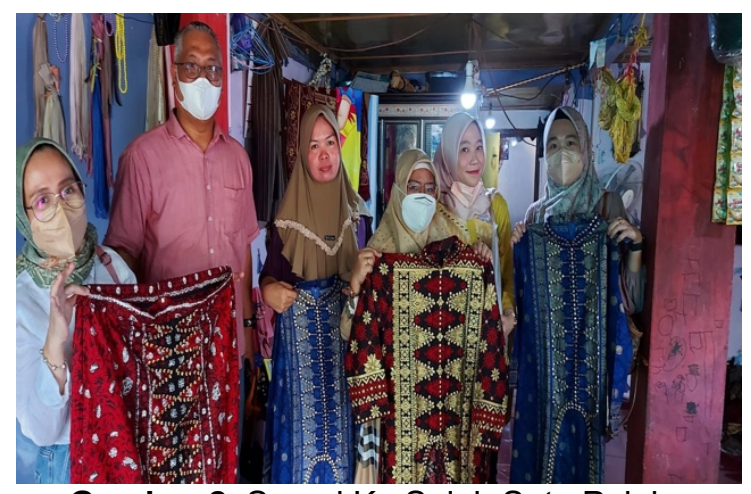

Gambar 2. Survei Ke Salah Satu Pelaku UMKM Bidang Usaha Konveksi

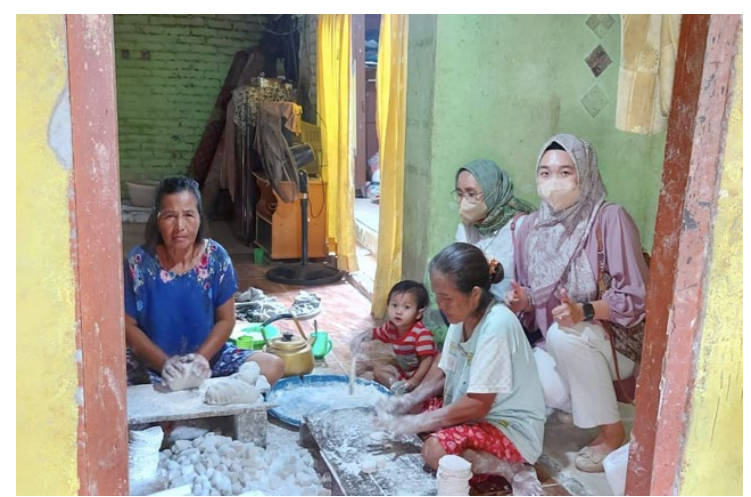

Gambar 3. Survei Ke Salah Satu Pelaku UMKM Bidang Usaha Kemplang Tunu

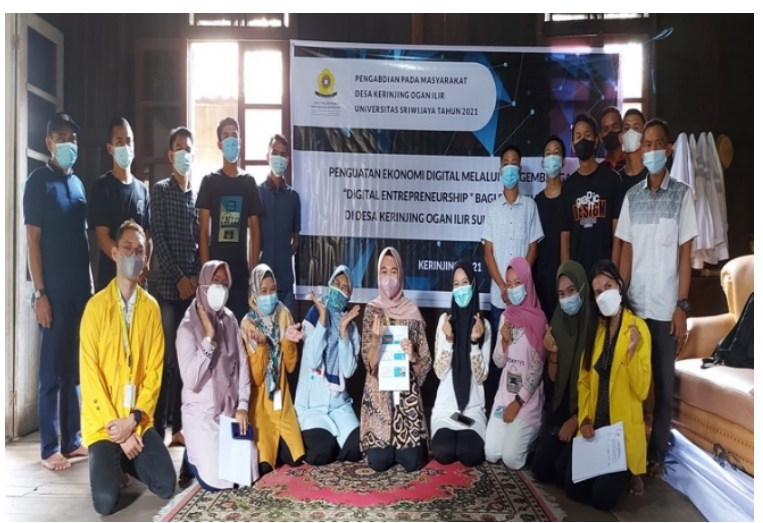

Gambar 4. Foto Bersama Peserta Pelatihan

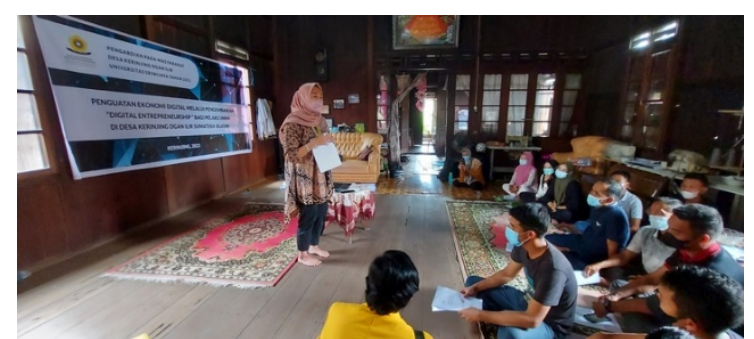

Gambar 5. Pemaparan Materi Oleh Nara Sumber

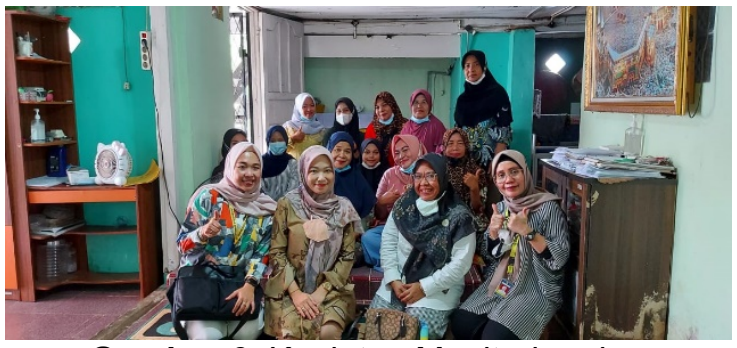

Gambar 6. Kegiatan Monitoring dan

Pendampingan dengan Pelaku UMKM
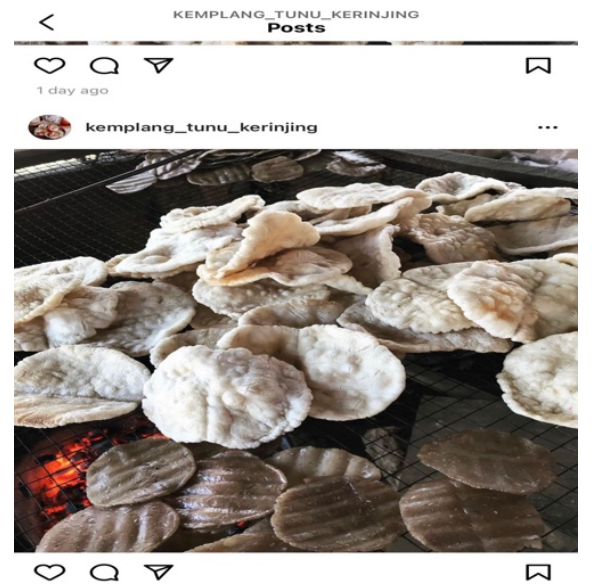

Gambar 7. Salah Satu Akun Instgram Pelaku UMKM di Desa Kerinjing Setelah pelaksanaan Kegiatan Pelatihan

\section{SIMPULAN DAN SARAN Simpulan}

Saat ini Pengembangan Digital Entrepreneurship di Indonesia dinilai masih rendah. Permasalahan ini juga dirasakan oleh UMKM yang ada di Provinsi Sumatera Selatan (Sumsel) salah satunya UMKM yang ada di Desa Kerinjing Ogan Ilir Sumatera Selatan. Masih banyak pelaku UMKM di desa kerinjing yang menjalankan usahanya secara konvensional dan belum beralih ke arah digita. Keterbatasan dalam menggunakan teknologi serta kurangnya edukasi dan pemahaman literasi digital disinyalir menjadi hambatan dalam pengembangan Digital Entrepreneurship bagi pelaku UMKM di desa kerinjing.

Kegiatan pelatihan dan pendampingan dalam pengembangan Digital Entrepreneurship bagi pelaku UMKM di Desa Kerinjing diharapkan dapat meningkatkan pengetahuan dan pemahaman literasi digital serta menumbuhkan motivasi bagi UMKM untuk dapat bertransformasi ke arah digitali sehingga para pelaku UMKM di desa kerinjing dapat menciptakan dan mengembangkan strategi bisnis yang lebih inovatif serta berdaya saing global yang dapat membantu penciptaan lapangan kerja dan meningkatan perekonomian desa. 


\section{Saran}

Adapun saran dari pelaksanaan kegiatan pengabdian masyarakat di Desa Kerinjing ini yaitu perlu dilakukan pengembangan Digital Entrepreneurship kepada para pelaku UMKM di Desa Kerinjing, mengingat saat ini perilaku konsumen yang cenderung lebih menyukai pembelian secara online melalui platform digital, sehingga dibutuhkan strategi bisnis yang lebih inovatif serta berdaya saing global untuk dapat menjangkau pasar yang lebih luas. Selain itu perlu adanya pelatihan lanjutan terkait dengan perancangan strategi pemasaran digital melalui platform media sosial dan E-Commerce dalam memasarkan dan menjual produk UMKM di Desa Kerinjing. Hal ini dilakukan agar para pelaku UMKM dapat menjangkau segmen pasar yang lebih luas dengan tujuan untuk meningkatkan volume penjualan dan bertahan pada bisnis yang semakin kompetitif.

\section{UCAPAN TERIMAKASIH}

Dalam kesempatan ini Penulis ingin mengucapkan terima kasih kepada seluruh pihak yang telah membantu baik secara moril maupun materil terhadap berlangsungnya kegiatan pengabdian kepada masyarakat ini. Terima kasih kami tujukan khususnya kepada Universitas Sriwijaya yang telah membantu pendanaan kegiatan ini, terima kasih juga kami sampaikan kepada Kepala Desa dan seluruh Pelaku UMKM di Desa Kerinjing yang telah bersedia untuk mengikuti seluruh rangkaian kegiatan pengabdian masyarakat ini.

\section{DAFTAR RUJUKAN}

Arianto, Bambang. (2020). Pengembangan UMKM Digital di Masa Pandemi Covid19. Jurnal Administrasi Bisnis, Vol.6, No.2.

Doi: https://doi.org/10.38204/atrabis.v6i2.51 2.

Avriyanti, Shinta. (2021). Strategi Bertahan Bisnis di Tengah Pandemi Covid-19 Dengan Memanfaatkan Bisnis Digital. Jurnal Pemikiran dan Penelitian Administrasi Publik dan Administrasi Bisnis, Vol.5, No.1. DOI 10.35722/pubbis.v5i1.380.

Deloitte. (2021). Mewujudkan Potensi Ekonomi Digital Indonesia. Deloitte Indonesia Perspectives. Edisi kedua. https://www2.deloitte.com/content/dam /Deloitte/id/Documents/aboutdeloitte/id-about-dip-edition-2-chapter4-id-feb2021.pdf , diakses 07 Juni 2021.

Giones, F., \& Brem, A. (2017). Digital technology entrepreneurship: A definition and research agenda. Technology Innovation Management Review, 7(5).

Ismansyah, Azandy., \& Kranggan, Buana. (2020). Technopreneurship Workshop Menggunakan E-Commerce. Jurnal Abdi Masyarakat, Vol. 6, No.1, 2020.

Kasidi. (2020). Tantangan Kewirausahaan di Era Ekonomi Digital. Journal of Economic Education and Entrepreneurship, Vol. 1, No.1, 2020, hlm. 17-23. Doi: https://doi.org/10.31331/jeee.v1i1.1223

Katadata. (2021). Riset: 63,4\% Pelaku UMKM Pesimistis Bisnis Tumbuh Tahun Ini. Katada.co.id. https://katadata.co.id/desysetyowati/di gital/6008265a6a385/riset-63-4pelaku-umkm-pesimistis-bisnistumbuh-tahun-ini , diakses 8 Juni 2021.

Katadata. (2020). Digitalisasi, Strategi UMKM Selamat dari Krisis. Katadata.co.id. https://katadata.co.id/katadatainsightsc enter/analisisdata/5f03cf11e0198/digit alisasi-strategi-umkm-selamat-darikrisis, diakses 8 juni 2021.

Kompas. (2020). Transformasi Digital, Kunci Vital Agar Bisnis Bisa Bertahan di Tengah Pandemi. Kompas.com. https://biz.kompas.com/read/2020/09/1 8/113428328/transformasi-digitalkunci-vital-agar-bisnis-bertahan-ditengah-pandemi , diakses 8 Juni 2021.

Kominfo. (2019). Perkembangan Ekonomi Digital di Indonesia. Jakarta : Pusat Penelitian dan Pengembangan Aplikasi Informatika dan Informasi.

Le Dinh, T., Vu, M.C. and Ayayi, A. (2018). "Towards a living lab for promoting the digital entrepreneurship process". International Journal of Entrepreneurship, Vol. 22 No. 1, pp. 117.

Mavilinda, H.F., Nazaruddin, A., Nofiawaty., Siregar, L.D., Andriana, I., \& Thamrin, K.M.H. (2021). "Menjadi UMKM Unggul" Melalui Optimalisasi Strategi Pemasaran Digital Dalam Menghadapi Tantangan Bisnis di Era New Normal. Journal of Sriwijaya Community Service, 2 (1): 17-28. Doi: https://doi.org/10.29259/jscs.v2i1.29 .

Merdeka.com. (2019). Mengenal Platform Pemasaran Digital Untuk Pebisnis Pemula. https://www.merdeka.com/teknologi/m engenal-platform-pemasaran-digitaluntuk-pebisnis-pemula.html, diakses 09 Juni 2021. 
Prastyaningtyas, E. W. (2019). Dampak Ekonomi Digital Bagi Perekonomian Indonesia. Seminar Nasional Manajemen Ekonomi Dan Akuntansi, (Fakultas Ekonomi UN PGRI Kediri), 103-108.

Sumarni, T., \& Melinda, L. D. (2020). Media Sosial dan E-commerce sebagai Solusi Tantangan Pemasaran Pada Masa Pandemi Covid-19 (Studi Kasus: UMKM Warung Salapan). ATRABIS: Jurnal Administrasi Bisnis, 6(2), 163171.

Doi: https://doi.org/10.38204/atrabis.v6i2.48 9.

Sumsel.idntimes.com. (2020). Baru 8\% UMKM di Sumsel Yang Manfaatkan Paltform Digital.

https://sumsel.idntimes.com/business/ economy/feny-agustin/baru-8-persenumkm-di-sumsel-yang-manfaatkaniplatform-idigital/3, diakses 9 Juni 2021.

Watts, Stephen. (2020). Digital Paltform: A Brief Introduction.

https://www.bmc.com/blogs/digitalplatforms/, diakses 09 juni 2021. 